\title{
HEREDOPATIA ATÁTICA POLINEURITIFORME
}

\author{
A. SPINA-FranÇA *
}

A. ANGHINAH **

L. C. Mattosinho-FrançA ***

Refsum observou em 1944-1945 os primeiros casos do quadro atualmente designado heredopatia atática polineuritiforme ${ }^{9}$, cabendo-lhe a individualização dessa entidade, embora Thiebaut e col. ${ }^{13}$, em 1961, tivessem reconhecido os caracteres da doença em caso por êles registrado em 1939.

Segundo Refsum ${ }^{9}$, caracteriza-se a doença por manifestações preponderantemente da esfera neurológica, destacando-se retinite pigmentar atípica com hemeralopia e redução concêntrica dos campos visuais, quadro polineurítico, ataxia, anosmia, alteraçōes pupilares, comprometimento da audição, ictiose cutânea e anomalias esqueléticas. Dissociação proteínocitológica no líquido cefalorraqueano, alterações eletrocardiográficas e quadro histopatológico de neurite intersticial hipertrófica são mencionados entre os achados mais freqüentes nos exames complementares. A doença costuma ter início insidioso e longa evolução, embora a sintomatologia inicial possa ser precipitada por infecções. Em tais ocasiões podem evidenciar-se os sintomas da doença em grupo ou isoladamente. Quando tais episódios ocorrem durante a evolução da moléstia, os modificações do quadro clínico resultantes lembram surtos de exacerbação da doença. É afecção de caráter familiar, com herança de tipo autossômico recessivo.

A doença parece resultar de êrro congênito do metabolismo lipídico relacionado a ocorrência anormal no organismo humano de um ácido graxo, o ácido fitânico (ácido 3,7,11,15-tetrametil-hexadecanóico) 1, 2,6,10, cujo achado no sôro é atualmente considerado fundamental para o diagnóstico ${ }^{i}$. Dietas pobres em ácido fitânico levam a que se observe melhoria na evolução de pacientes com a doença ${ }^{4}$.

Em 1967, Nevin e col. ${ }^{7}$ referiam que pouco mais de 40 casos da doença foram registrados na literatura, segundo distribuição geográfica que sugere a possibilidade de serem os pacientes de origem escandinava.

O caso presente é registrado porque apresentava o paciente muitas das características descritas na doença de Refsum. Como não fôssem encontrados nêle alguns dos elementos mais freqüentemente descritos no quadro clínico da doença e não pudessem ter sido completados estudos sôbre seu

Trabalho da Clinica Neurológica da Fac. Medicina da Univ. de São Paulo (Prof. A. Tolosa): * Professor assistente e Docente Livre; ** Assistente; *** Médico-Chefe do Serviço de Anatomia Patológica do Hospital do Servidor Público Estadual de São Paulo. 
metabolismo lipídico, especialmente no que se refere à demonstração da presença ou não do ácido fitânico, preferimos discutir as possíveis interrelações do caso com a heredopatia atática polineuritiforme.

\section{OBSERVAÇĀO}

I. E.S. (registro H.C. n.9 791.819) - Paciente branco, do sexo masculino, com 32 anos de idade, procedente do interior do Estado de Minas Gerais e atendido na Cuínica Neurológica a partir de janeiro-1966. Nascido a têrmo, de parto normal, sem passado mórbido de monta, apresentou, aos 17 anos, episódio infeccioso agudo, depois do qual passou a queixar-se de diminuição da acuidade auditiva e de tonturas. Essa sintomatologia permaneceu inalterada até cêrca de 6 meses antes de ser atendido. Desde ersa ocasião houve agravamento progressivo da hipoacusia e surgiu tendência à queda durante a marcha. Posteriormente passou a apresentar fraqueza nos membros inferiores e nas mãos e a queixar-se de dôres em agulhada nas faecs plantares dos pés.

No exame foi encontrada ictiose cutânea que predominava nos membros inferiores e no dorso (Fig. 1). Nada foi verificado de interêsse no restante do exame clínico, inclusive no do aparêlho cardiovascular. No exame neurológico foram evidenciados: ataxia de tipo misto, alterações motoras e sensitivas nos membros e comprometimento de alguns nervos cranianos. A ataxia era caracterizada por dificuldade na manutencão da posição ereta e marcha de tipo ebrioso. Com o fechamento dos olhos o quadro se agravava, surgindo oscilações e tendência à queda, bem como desvios na marcha. Essas manifestaçōes não apresentavam direção ou sentido predominante e não sofriam a influência de modificaçōes da posição da cabeça. Havia também incoordenação apendicular, sendo nitida a dismetria nos membros inferiores, nos quais se intensificava quando pesquisada fora de contrôle visual. O comprometimento motor caracterizava-se por diminuição discreta da fôrça muscular nas extremidades dos membros, mais evidente nas dos membros infericres, nos quais se tornava manifesta (especialmente no direito) mediante o emprêgo de manobras deficitárias. Tono e trofismo musculares normais. Reflexos miotáticos clônicos profundos presentes e simétricos, sendo vivas as respostas dos reflexos patelar e aquiliano, bilateralmente; dos superficiais, achavam-se abolidos os reflexos cremasterinos. Havia comprometimento da sensibilidade táctil, da dolorosa, da palestésica e da segmentar: hipoestesia táctil nas faces palmares das māos e nas extremidades dos membros inferiores, a partir do têrço distal das pernas; hiperalgesia nas faces plantares dos pés; hipopalestesia nos membros inferiores, mais acentuada nas suas porções distais; anartrestesia ao nivel dos artelhos. $\checkmark$ exame dos nervos cranianos mostrava comprometimento visual caracterizava-se por diminuição bilateral da acuidade, mais acentuada à esquerda; fundos oculares normais; perimetria dos campos visuais normais. O comprometimento da motricidade ocular caracterizava-se por déficit do abducente do lado esquerdo e por diminuição do reflexo fotomotor direto da pupila esquerda; diâmetros pupilares, reflexos fotomotores consensuais e de acomodação pupilar, normais. O comprometimento da audição era acentuado, havendo hipoacusia bilateral com perda de 80 a $90 \mathrm{db}$. Nistagmo horizontal bilateral, à execução lateral do olhar.

Evolução - O paciente permaneceu sob contrôle até novembro-1966. Durante êsse periodo não ocorreram modificações do estado clínico.

Estudo da familia do paciente - Família de nivel cultural baixo, pouco sabendo informar além do que se refere aos avós do paciente, seus pais, irmãos e sobrinhos. Os avós e pais eram brancos e são falecidos não havendo informações precisas sôbre a doença que acarretou sua morte. Os pais não eram consangüineos c tiveram 5 filhos, todos vivos, sendo o paciente o último. $O$ avô paterno tinha pele semelhante à do paciente; dos parentes vivos, um irmão e pelo menos 4 sobrinhos do paciente apresentam também alterações cutâneas semelhantes. Foram examinados dois irmãos do paciente e dois sobrinhos. Apresentavam ictiose cutà- 

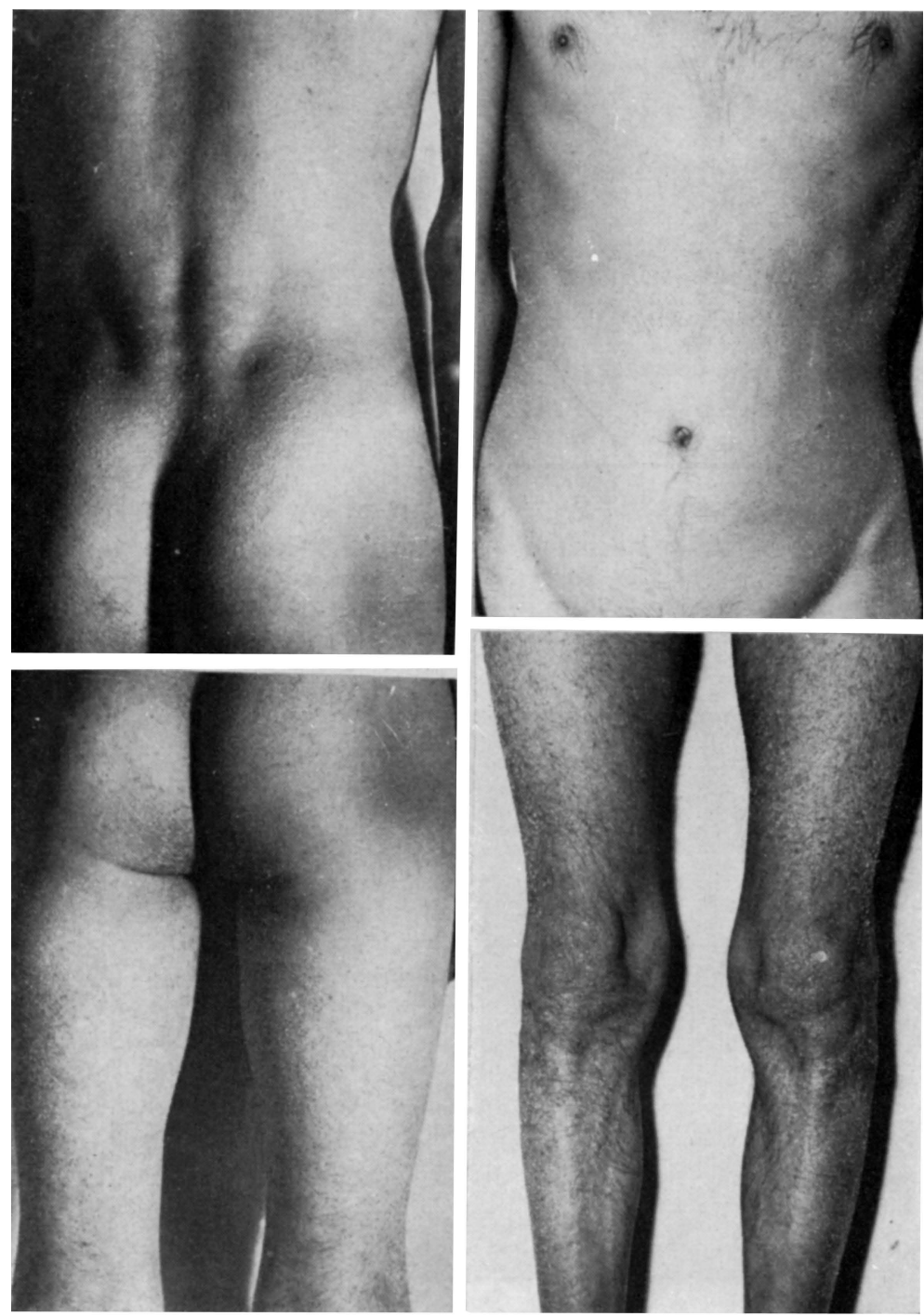

Fig. 1 - Caso I.E.S. - Fotografias do tronco e dos membros inferiores do paciente, mostrando a ictiose cutânea.

nea um dos irmãos e seus dois filhos. Em nenhum dêles foram encontrados distúrbios neurológicos (Quadro 1).

Exames complementares - Exames radiológicos - nos pés, hallux valgus bilateralmente (Fig. 2); ossos das mãos, pés, articulações do cotovêlo e dos joelhos com desmineralização difusa, sem alteraçōes das interlinhas articulares; crânio normal. Eletrocardiograma dentro dos limites normais. Exame eletromiográfico e eletrodiagnóstico (músculos tibial anterior direito, gastrocnêmio direito, quadriceps direito e primeiro interósseo dorsal da mão direita) dentro dos limites normais. 


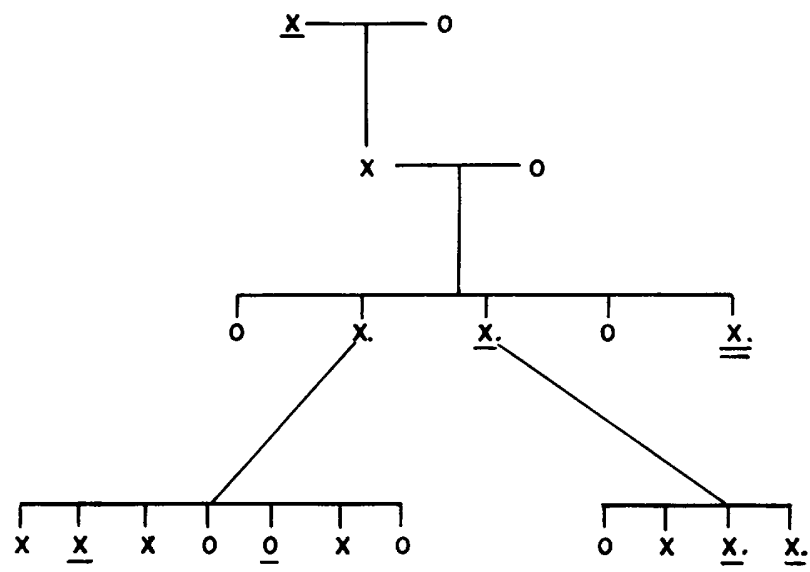

Quadro 1 - Familia do paciente I.E.S. :(X) masculino; (O) feminino; os parentes com ictiose cutânea acham-se assinalados por grifo e os examinados, por um ponto. $O$ paciente estudado acha-se assinalado por dois gripos e ponto.

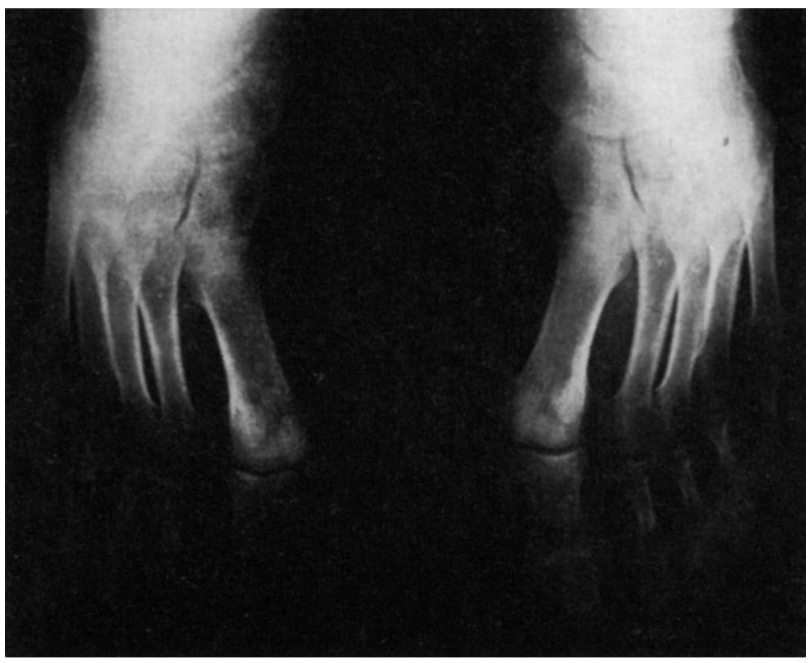

Fig. 2 - Caso I.E.S. - Radiografia dos pés do paciente, mostrando hallux valgus, bilateralmente.

Eletrencefalograma: disritmia paroxistica nas áreas temporais de ambos os hemisférios, caracterizada por surtos independentes de ondas lentas irregulares, pequenos grupos de ondas hipersíncronas e ondas "sharp". Reações para sífilis no sôro sangüineo (r. Wassermann, r. Kahn, r. Kline) negativas. Exames bioquimicos no söro sangüineo * - Proteinograma (resultados em g/100 ml): albumina 3,94; globulinas: alfa-1 0,27, alfa-2 0,94, beta 0,98, gama 1,67. Cobre 141 micro g/100 ml;

* Os autores agradecem ao Dr. F. B. De Jorge pelas determinações de cobre, enxôfre, magnésio e ceruloplasmina. 
Enxôfre $1,883 \mathrm{mg} / 100 \mathrm{ml}$; Magnésio 2,126 $\mathrm{mEq} / \mathrm{l}$; Ceruloplasmina $39,8 \mathrm{mg} / 100 \mathrm{ml}$. Transaminases (método de Reitman e Frankel): glutâmico-oxalacética 45 unidades, glutâmico-pirúxica 52 unidades. Exame do liquido cefalorraqueano: punção lombar (paciente em decúbito lateral); pressão inicial $15 \mathrm{~cm}$ de água; liquor límpido e incolor; 2 células por $\mathrm{mm}^{2}$; proteínas totais $21 \mathrm{mg} / 100 \mathrm{ml}$; reações para sifilis (x. Wassermann e r. do VDRL) negativas; reação de fixação do complemento para cisticercose negativa; eletroforese das proteinas (resultados em percentagem): préalbumina 2,1; albumina 45,5; globulinas: alfa-1 5,7, alfa-2 11,0, beta 19,1, taú 3,6 , gáma 13,0. Exames histopatológicos - Nervo periférico (ramo maleolar do nervo tibial, obtido mediante biópsia, coloração por hematoxilina-eosina): no sentido longitudinal os fragmentos dos ramusculos nervosos mostram arquitetura aparentemente normal, havendo discreto aumento quantitativo de células de Schwann; os cortes transversais mostram consideráveis alteraçōes arquiteturais, as fibras apresentando calibre muito aumentado, notando-se, em sua periferia, arranjo concôntrico de células de Schwann, por vêzes com aspecto imbricado; a mielina apresenta em algumas fibras aspecto vacuolizado; não há reação inflamatória; as arteríolas e vênulas não apresentam alterações histológicas (Fig. 3). Diagnóstico: nervo periférico com alterações compatíveis com o diagnóstico de neurite intersticial hipertrófica. Biopsia de pele (face dorsal do antebraço): a epiderme mostra espessamento difuso da camada córnea; em alguns campos nota-se a presença de curtas projeções papilares, recobertas por lâminas de queratina, que fazem saliência na superfície externa; a camada de células granulosas é desenvolvida ao longo de tôda a extensão da epiderme; a camada de células malpighianas é focalmente espessada, com alongamento das cristas epiteliais profundas. Derma formado por tecido conjuntivo denso, sem alteraçōes histológicas. Diagnóstico: pele com discreta hiperqueratose epidérmica.

\section{COMENTARIOS}

Quadro clínico - Richterich e col. ${ }^{11}$ puseram em destaque o pleomorfismo sintomatológico da doença ao analisarem 37 casos registrados até 1962. Assinalaram um total de 39 sinais e consideraram como não característicos 11 dêles por ocorrerem em menos de um têrço dos casos; as 28 alterações restantes foram consideradas como mais características, embora não ocorram tôdas num mesmo caso. Destacam-se entre elas, pela freqüência, a pclineuropatia periférica de evolução crônica, provocando alterações sensitivo-motoras e predominando nos membros inferiores, a ataxia de tipo misto, o nistagmo, as alterações da sensibilidade profunda de tipo cordonal, a anosmia, o comprometimento da motricidade ocular (especialmente da motricidade ocular intrínseca, provocando miose e perda de reflexos fotomotores), o comprometimento neurogênico da audição chegando até a surdez, as manifestações oculares (hemeralopia, retração concêntrica dos campos visuais, opacificação do cristalino e pigmentação anormal da retina que ocasionalmente assume o aspecto de retinite pigmentar), as manifestações ósseas inespecíficas (espondilite, cifo-escoliose, dedos em martelo, pés cavos e displasias epifisárias) e malformações, como o encurtamento dos ossos do metatarso e/ou do metacarpo, as alterações ictiosiformes da pele, especialmente nos pacientes cuja doença se manifestou na juventude, as manifestaçōes cardiovasculares na maioria dependentes de alterações na condução do estimulo e/ou de comprometimento do miocárdio. Avaliando a evolução da dcença, chamaram os autores a atenção para o fato de ser lenta na maioria dos casos, marcada por surtos de agravamento após os quais pode ocorrer 
remissão parcial dos sintomas; infecções ou gestação podem desencadear tais surtos. O quadro neurológico se agrava de modo lento e progressivo. Em geral, a morte decorre do comprometimento cardíaco ou de complicações respiratórias.

No caso ora registrado, os sinais próprios à polineuropatia periférica eram discretos; já a ataxia era patente, bem como o nistagmo e o compro-
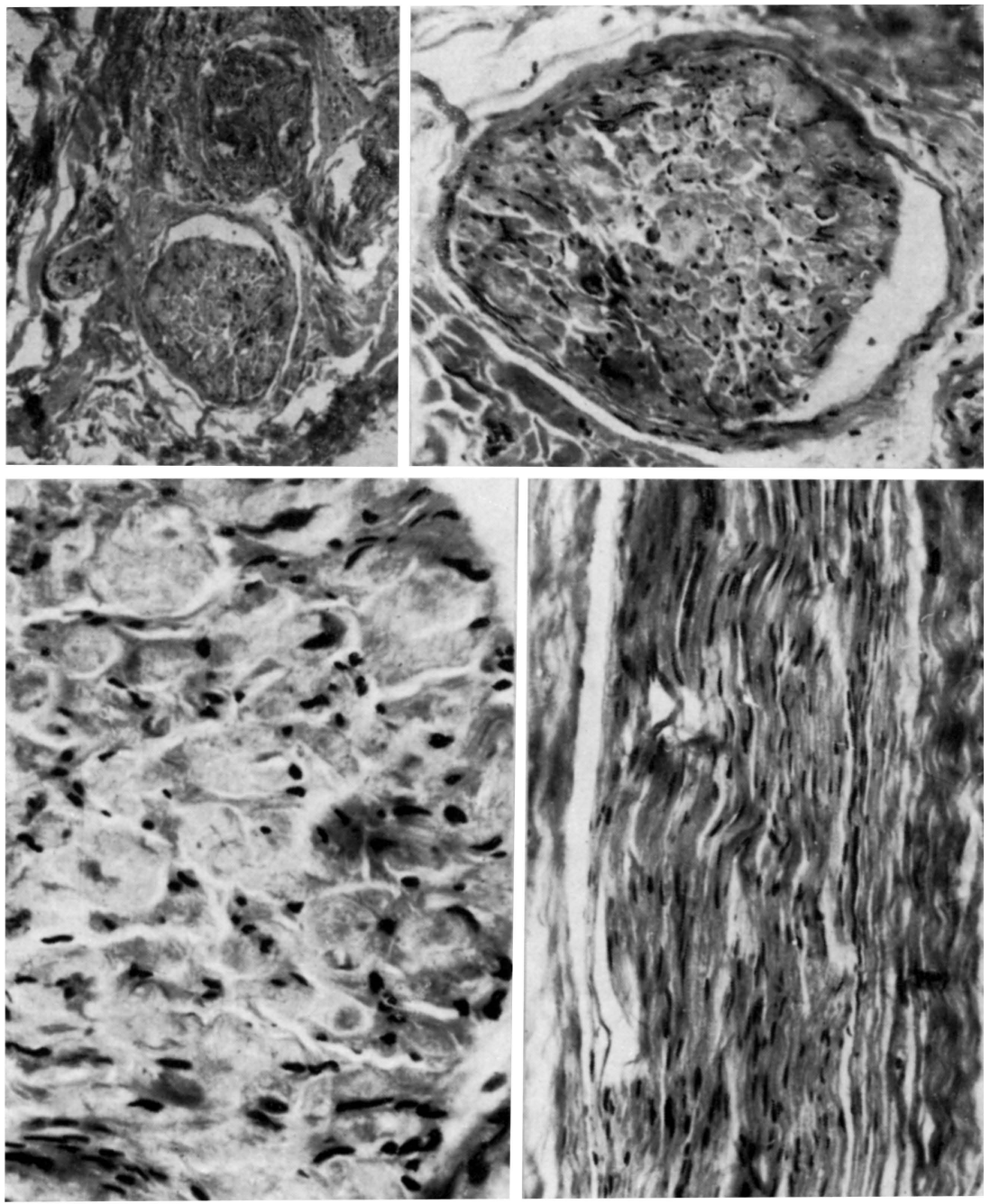

Fig. 3 - Caso I.E.S. Microfotografias de cortes de ramo maleolar do nervo tibial, corados por hematoxilina-eosina. No alto, corte transversal em pequeno $e$ em médio aumento (à esquerda e à direita, respectivamente). Em baixo, corte transversal em maior aumento (à esquerda) e corte longitudinal em médio aumento (à direita). Vide descrições no texto. 
metimento da sensibilidade profunda. Havia diminuição da acuidade visual, comprometimento da motricidade ocular intrinseca e extrínseca e da audição. Havia também desmineralização óssea difusa e ocorrência de hallux valgus em ambos os pés. Foram também constatadas alterações cutâneas ictiosiformes. Por outro lado, não foram verificadas alteraçōes cardiovasculares e oculares. A sintomatologia inicial desencadeou-se após episódio infecciczo agudo e os sintomas que surgiram nessa época não regrediram. Um segundo surto de piora ocorreu cêrca de 6 meses antes da observação inicial do paciente. Desde então e durante o período em que pôde ser acompanhado não ocorreram novos surtos de piora.

Do ponto de vista do quadro clínico e da evolução da doença, os sinais e sintomas apresentados pelo paciente cujo caso é registrado são idênticos àqueles que são considerados entre os mais comuns na doença. Alterações eletrencefalográficas não são mencionadas como parte do ccmplexo sintomatológico principal da doença; no entanto, Veltema e Verjaal ${ }^{15}$ registraram caso no qual havia modificações do eletrencefalograma próximas daquelas descritas no caso presente.

Quadro bioquímico - Segundo a revisão de Richterich e col. ${ }^{11}$ destacam-se entre estas alterações a dissociação proteíno-citológica no LCR e, no sôro, a elevação das concentrações de ácidos graxos, cobre, ácido N. acetil-neuranímico, cerulosplasmina, transaminases, creatinoquinase e deidrogenase lática, bem como diminuição de colinesterase.

A hiperproteinorraquia que é descrita como um dos dados laboratoriais mais comuns, não foi registrada no caso presente. Não se pode excluir que tal se deva ao fato de o paciente ter sido examinado durante periodo de estabilização da doença, já que costuma ocorrer aumento de proteinorraquia quando surtos de exacerbação se tornam manifestos ${ }^{15}$.

No caso aqui relatado não foi possivel fazer dosagem de ácidos graxos totais nem a pesquisa do ácido fitânico, dado considerado de primeira importância no estabelecimento do diagnóstico. No entanto, não se pode excluir que o aumento de enxôfre no sôro esteja na dependência de modificaçōes do metabolismo lipídico. Foi verificado aumento de concentração de cobre, de ceruloplasmina, de transaminases glutâmico-oxalacética e glutâmico-pirúvica no sôro. $\mathrm{O}$ ácido neuranímico, a fosfocreatinoquinase, a deidrogenase lática e a colinesterase não foram determinadas. O proteínograma do sôro mostrava aumento de globulina alfa-2 e o fracionamento eletroforético das proteínas do liquido cefalorraqueano não demonstrou alterações. Êste último dado confirma resultados já obtidos por outros pesquisadores, como Ashenhurst e col. (citados por Refsum ${ }^{9}$ ).

Quadro anátomo-patológico - A distribuição das lesões do sistema nervoso central guarda alguma semelhança com as observadas em certas heredodegenerações espinocerebelares, havendo dados que sugerem distúrbios do metabolismo lipídico ${ }^{9}$, lembrando mesmo a ocorrência de tesaurismose sudanófila 14. Tais lesões são encontradas predominantemente na medula e no tronco cerebral. Na medula tem sido verificada atrofia dos funiculos posteriores (especialmente do funículo grácil), cujas bainhas de mielina mostram-se pálidas; há também infiltração de células gordurosas e gliose; nos 
neurônios de coluna cinzenta anterior foram assinalados sinais de degeneração retrógada. Dentre as lesões do tronco cerebral destacam-se: desmielinização nos lemniscos mediais, pedúnculos cerebelares superiores e inferiores, tratos rubrospinais, olivocerebelares e ao redor dos núcleos denteados; alterações degenerativas nas células dos núcleos olivares inferiores, do vago, vestibulares, cocleares, rubro e denteado. A presença de células gordurosas e a ocorrência de gliose também são referidas nesses niveis. As leptomeninges e plexos corióides podem apresentar sobrecarga sudanófila.

Nos nervos periféricos tem sido encontrado quadro de neuropatia intersticial hipertrófica, com espessamento irregular de troncos nervosos devido a aumento local do endoneuro. Alguns cilindroeixos apresentam espessamento e tumefação segmentar e, cutros, atrofia. Há redução das baínhas de mielina que se reduzem, por vêzes, a delgada borda junto ao cilindroeixo, e ocorre proliferação das células de Schwann. Esta última alteração e o aumento do endoneuro levam ao aspecto de bulbos de cebola verificados nas neuropatias intersticiais hipertróficas ${ }^{3}$. Depósitos sudanófilos podem ser também encontrados após a atrofia da baínha de mielina.

No caso registrado, o quadro de polineuropatia instalara-se recentemente. Mesmo assim a biopsia de ramo maleolar do nervo tibial permitia evidenciar alterações compativeis com o diagnóstico de neurite intersticial hipertrófica. Não foram encontradas áreas de desmielinização completa nem de atrofia dos cilindroeixos, fato a que talvez possa ser relacionada a normalidade dos exames neuroelétricos praticados. Havia aumento de calibre de fibras e, em algumas delas, a mielina apresentava aspecto vacuolizado; as células de Schwann dispunham-se em arranjo concêntrico, por vêzes assumindo aspecto imbricado.

Quadro familiar - Apenas o paciente estudado apresentava polineuropatia atática nas gerações sôbre as quais puderam ser obtidas informações, fato que o aproxima do caso registrado por Olesen ${ }^{8}$ e considerado por êle como atípico. No caso relatado por êste autor não foram assinaladas as manifestações oculares clàssicamente descritas e o quadro polineuritico também era discreto.

A ocorrência da ictiose na familia sugere que ela represente um dos "defeitos congênitos menores" descritos como freqüentes em famílias nas quais incidem afecções heredodegenerativas de caráter mais definido, como salientou recentemente Hallgren a propósito da retinite pigmentar ${ }^{5}$. Pela análise da distribuição da ictiose na família do paciente estudado, não se pode excluir herança de tipo autossômico recessivo. Este tipo de herança é o descrito para a ictiose na doença de Refsum ${ }^{16}$. Em certas famílias em que incide a doença de Refsum têm sido assinalados outros defeitos congênitos menores, como seja, a incidência de pés cavos ${ }^{2}$.

As alterações metabólicas da heropatia atática polineuritiforme vieram reabrir o estudo de numerosas afecções heredo-familiares, especialmente daquelas incluídas no grupo das heredodegenerações espinocerebelares, no sentido de procurar esclarecer as possiveis alterações metabólicas que podem caracterizá-las. Recentemente Rosenberg e Chutorian ${ }^{12}$ procuraram 
estabelecer interrelaçōes entre a doença de Refsum e outras heredodegenerações, como a atrofia óptica hereditária, a surdez familiar, a neuropatia sensorial hereditária, as doenças de Charcot-Marie-Tooth e de Friedreich, e as demais degenerações espinocerebelares de caráter hereditário. Essas interrelações foram apontadas a propósito do estudo de três pacientes de uma família com degeneração opto-acústica e polineuropatia, quadro que consideraram mais próximo à doença de Charcot-Marie-Tooth que da de Refsum. Os autores ccnsideraram a relação com esta última como menos provável uma vez que, no quadro clínico dos pacientes, não havia ataxia, retinite pigmentar, alterações ósseas e cardiacas e ictiose e, no quadro bioquímico, hiperproteinorraquia e presença anormal de ácido fitânico.

O caso ora registrado acha-se mais próximo da heredopatia atática polineuritiforme, pois no quadro clínico só não havia manifestações oculares e cardíacas e, no bioquímico, hiperproteinorraquia. Não foi possivel estudar os ácidos graxos, o que teria facilitado sobremaneira o estudo. Os demais dados clínicos e bioquímicos e histopatológicos que foram evidenciados têm sido descritos na doença de Refsum, fato que aproxima desta última o caso ora estudado.

\section{RESUMO}

Registro de caso de paciente com quadro mórbido relacionável ao da heredopatia atática polineuritiforme (doença de Refsum). O diagnóstico é discutido frente aos aspectos clínicos, laboratoriais e histopatológicos encontrados e sua relação com os achados referidos na literatura como próprios a essa moléstia.

\section{SUMMARY}

\section{Heredopathia atactica polyieuritiformis.}

The case of a patient with many of the clinical characteristics commonly referred to in Refsum's disease is reported. Ichthyosis was noted in the patient and in other members of the family. Cerebrospinal fluid proteins were normal. Serum copper and caeruloplasmin concentrations were hight, as well as transaminases. Histological findings common to neuritis interstitialis hypaertrophica were found on examination of a peripheric nerve segment obtained by biopsy. Studies on the occurrence of phytanic acid could not be carried out. The relationship between the case reported and Refsum's syndrome is discussed.

\section{REFERENCIAS}

1. ALEXANDER, W. S. - Phytanic acid in Refsunm's syndrome. J. Neurol. Neurosurg. Psychiat. 29:412-416, 1966.

2. BONDUElle, M.; BOUYGues, P.; LORMEAU, G.; DElouX, D.; LAUDAT, P. \& WOLF, L. M. - Maladie de Refsum: étude des lipides du sérum et des urines. Rev. Neurol. 115:933-942, 1966. 
3. CAMMERMEYER, J. - Neuropathological changes in hereditary neuropathies: manifestation of the syndrome heredopathia atactica polyneuritiformis in the presence of interstitial hypertrophic polyneuropathy. J. Neuropath. exp. Neurol. 15:340-361, 1956.

4. ELDJARN, L.; TRY, K.; STOKKE, O.; MUNTHE-KAAS, A. W.; REFSUM, S.; STEINBERG, D.; AVIGNAN, J. \& MIZE, C. - Dietary effects on serum phytanic acid levels and on clinical manifestations in heredopathia atactica polyneuritiformis. Lancet i:691-693, 1966.

5. HALLGREN, B. - Retinitis pigmentosa combined with congenital deafness, with vestibulo-cerebellar ataxia and mental abnormality in a proportion of cases. A clinical and genetic-statistical study. Acta psychiat. neurol. Scand. suppl. 138, 1959.

6. KLENK, E. \& KAHLKE, W. - Ueber das Vorkommen der 3,7,11,15-tetramethylhexadecansaure (phytansaure) in dem Cholesterin estern und anderen Lipoidfraktionen der Organe bei einem Krankheitsfall unbekannten Genese (Verdacht auf Heredopathia atactica polyneritiformis: Refsum syndrome). Hoppe-Seyler Z. Phys. Chem. 333:133-139, 1963.

7. NEVIN, N. C.; CUMINGS, J. N. \& McKEOWN, F. - Refsum's syndrome: heredopathia atactica polyneurtiformis. Brain 90(II):419-428, 1967.

8. OLESEN, T. B. - A case of heredopathia atactica polyneuritiformis (morbus Refsum). Acta psychiat. neurol. scand. 32:83-88, 1957.

9. REFSUM, S. - Heredopathia atactica polyneuritiformis. Wld, Neurol. 1:334372,1960 .

10. RICHTERICH, R.; van MECHELEN, P. \& ROSSI, E. - Refsum's disease (heredopathia atactica polyneuritiformis): an inborn error of lipid metabolism with storage of 3,7,11,15-tetramethyl hexadecanoic acid. Amer. J. Med. 39: 230-236, 1965.

11. RICHTERICH, R.; MOSER, H. \& ROSSI, E. - Refsum's disease (heredopathia atactica polyneuritiformis): an inborn error of metabolism with storage of 3,7,11,15-tetramethyl hexadecanoic acid. Humangenetik 1:322-332, 1965.

12. ROSENBERG, R. N. \& CHUTORIAN, A. - Familial optoacoustic nerve degeneration and polyneuropathy. Neurology (Minneapolis) 17:827-832, 1967.

13. Thiebaut, F.; Lemoyne, J. \& Guillaumat, L. - Maladie de Refsum. Rev. Neurol. 104:152-154, 1961.

14. Van BOGAERT, L.; MECHELEN, P.; MARTIN, J. J. \& GUAzZI, G. C. Sur la neuropathologie de la maladie de Refsum-Thiébaut. Rev. Neurol. 116: 229-240, 1967.

15. VELTEMA, A. N. \& VERJAAL, A. - Sur un cas d'hérédopathie ataxique polyneuritiforme: maladie de Refsum. Rev. Neurol. 104:15-23, 1961.

16. WELLS, R. S. \& KERR, C. B. - Genetic classification of ichthyosis. Arch. Dermat. 92:1-6, 1965.

Clinica Neurológica - Faculdade de Medicina da Universidade de São Paulo Cuixa Postal 3461 - São Paulo, SP, Brasil. 